Cahiers d'études africaines

$211 \mid 2013$

Varia

\title{
Calame-Griaule, Geneviève. - Ethnologie et langage
}

\section{Éric Jolly}

\section{OpenEdition}

Journals

Édition électronique

URL : http://journals.openedition.org/etudesafricaines/14495

DOI : 10.4000/etudesafricaines.14495

ISSN : $1777-5353$

Éditeur

Éditions de l'EHESS

Édition imprimée

Date de publication : 16 septembre 2013

Pagination : 735-737

ISBN : 978-2-7132-2388-4

ISSN : 0008-0055

Référence électronique

Éric Jolly, «Calame-Griaule, Geneviève. - Ethnologie et langage », Cahiers d'études africaines [En ligne], 211 | 2013, mis en ligne le 10 octobre 2013, consulté le 24 septembre 2020. URL : http://

journals.openedition.org/etudesafricaines/14495; DOI : https://doi.org/10.4000/etudesafricaines. 14495

Ce document a été généré automatiquement le 24 septembre 2020.

(C) Cahiers d'Études africaines 


\title{
Calame-Griaule, Geneviève. - Ethnologie et langage
}

\author{
Éric Jolly
}

\section{RÉFÉRENCE}

CALAME-GRIAULE, Geneviève. - Ethnologie et langage. La parole chez les Dogon. Troisième

édition revue et corrigée, Limoges, Lambert-Lucas, 2009, 600 p., bibl., ill.

1 Pour cette seconde réédition d'Ethnologie et langage, une présentation critique de l'ensemble de l'ouvrage serait redondante par rapport à la quinzaine de comptes rendus consacrés aux éditions précédentes $(1965,1987)$. En revanche, il est intéressant d'analyser avec un recul de près de cinquante ans la place singulière qu'occupe ce livre dans l'histoire de l'ethnologie française. S'il se situe en partie dans la continuité des célèbres travaux de Marcel Griaule et de son équipe, il s'en démarque également sur de nombreux points théoriques et méthodologiques, en particulier au niveau de son approche de la langue, des discours et des récits oraux. En France, ce premier livre de Geneviève Calame-Griaule - qui est aussi sa thèse - a d'ailleurs ouvert la voie aux études ethno-linguistiques. En outre, en dépit de l'empreinte évidente de Griaule et de ses informateurs sur la première moitié de l'ouvrage, l'auteure porte sur la société dogon un regard qui n'est déjà plus celui de la génération précédente.

Spécialisé dans les sciences du langage, le nouvel éditeur - Lambert-Lucas - a fait le choix justifié et méritoire d'ajouter au texte originel, pourtant imposant, trois présentations ou analyses qui permettent justement de mieux saisir l'importance de ce livre dans l'œuvre de Geneviève Calame-Griaule et dans le champ des études ethnolinguistiques. Rédigé à l'occasion de la traduction anglaise de 1986, le premier de ces textes (par ordre chronologique) est signé de l'Américain Dell Hymes, l'un des fondateurs de l'ethnographie de la communication. Les deux suivants, écrits par l'auteure, sont la postface à la réédition française de 1987 et la préface à l'édition de 2010. Sources d'informations inédites sur l'histoire de ce livre et sur le parcours ou 
l'héritage scientifique de Calame-Griaule, ces textes complémentaires compensent largement, par leur intérêt, la qualité moyenne de l'impression et des reproductions photographiques.

3 Évidente dès la lecture de l'avant-propos, l'influence de Griaule était inévitable dans le cas d'un livre écrit par sa fille à partir d'enquêtes menées sur «son » terrain, sous sa direction (pour la mission préliminaire de 1946, exclusivement linguistique) ou auprès des mêmes informateurs et interprètes (entre 1954 et 1960). En outre, il faut rappeler qu'Ethnologie et langage paraît la même année que le monumental ouvrage posthume de Griaule, cosigné par Germaine Dieterlen: Le Renard pâle (Paris, Institut d'ethnologie, 1965). Cette influence paternelle se manifeste d'abord à travers le thème de la parole, déjà traité dans Dieu d'eau (1948) sous l'angle du mythe. Plus concrètement, les travaux antérieurs de l'École Griaule alimentent, dans Ethnologie et langage, les deux parties introductives sur la conception de la parole, en particulier celle centrée sur la mythologie. L'auteure reprend ainsi, pour les compléter, les informations de son père (ou de ses informateurs) sur les mythes, les correspondances symboliques, les classifications, les composantes de la personne, les niveaux de savoir et les représentations graphiques des Dogon, en leur donnant toutefois unéclairage plus psychologique et une interprétation plus «structurale » sous 1'influence conjointe de Claude Lévi-Strauss et de la psychanalyse.

4 Basée en grande partie sur les données publiées par Griaule, cette première moitié d'ouvrage est justement la moins convaincante, du moins quand on la relit aujourd'hui (à l'exception notable des analyses sémantiques sur la notion de parole ou du chapitre sur les représentations populaires de la production de paroles). Une telle partie apparaît rétrospectivement comme un héritage filial que l'auteure voulait assumer avant de passer à des recherches plus personnelles et novatrices sur les pratiques langagières, présentées dans la seconde moitié du livre (puis poursuivies au cours des années sous d'autres angles et sur d'autres terrains). De fait, après 1965, Geneviève Calame-Griaule n'a jamais retravaillé sur les grandes thématiques de recherche privilégiées par Griaule après-guerre: cosmogonies, peintures ou signes graphiques, taxinomies... Il faut ajouter que l'auteure reste souvent prudente lorsqu elle suit les analyses de son père. Consciente que ses tableaux de correspondances symboliques sont des modèles construits en partie par l'enquête, elle ne les présente pas comme des données figées, mais comme des exemples « de la manière dont les Dogon établissent leurs correspondances entre les catégories " (note 2, p. 184). C'est déjà une nuance de taille par rapport aux travaux de Griaule et Dieterlen.

5 Avec ses 250 pages, la troisième partie sur «la parole vécue » est de loin la plus importante, mais aussi la plus originale et la plus représentative de l'œuvre de CalameGriaule. Sans jamais perdre de vue la réalité observable, les évolutions en cours et les singularités individuelles, l'auteure décrit, à partir d'observations personnelles ou de témoignages individuels, les mécanismes d'apprentissage linguistique, les échanges verbaux de la vie courante (avec leurs règles et leur gestuelle), les expressions sonores des émotions et les différents usages de la parole (poétique, amoureux, religieux, euphémique, cathartique, agonistique, thérapeutique...). En combinant anecdotes significatives, récits d'informateurs, observations détaillées, extraits de chants et plaisanteries conjugales, le magnifique chapitre sur « la parole dans la vie amoureuse » fournit par exemple une description savoureuse et une analyse fine et inédite des flirts juvéniles, des échanges verbaux entre époux et des rapports entre les sexes. Attentive 
aux effets de sens produits par les situations discursives, Calame-Griaule n'est jamais dupe du discours normatif des hommes qui, s'ils dénigrent volontiers les femmes en général, vantent en aparté les mérites de celles qui leur sont proches et adoptent avec elles des conduites relativement éloignées des règles qu'ils décrivent. Pour les mêmes raisons, l'auteure remet en cause l'idée d'une stricte étanchéité des secrets masculins ou féminins en montrant que ceux-ci reposent en partie sur une ignorance feinte de l'autre sexe.

6 Les deux chapitres suivants sur la parole dans la vie sociale et religieuse rendent compte de l'importance des procédés stylistiques et du contexte d'énonciation pour saisir le sens, l'intention et l'efficacité d'une prière, d'un serment, d'une malédiction, d'une insulte ou d'un silence. Combinant analyses structurales et approche ethnolinguistique, le cinquième chapitre sur "l'art de la parole » examine avec la même finesse les contes, devinettes, proverbes, chants et devises dogon en étudiant aussi bien les règles ou les situations de leur énonciation que leurs caractéristiques stylistiques, leurs variantes, leur évolution, leur structure, leur dimension performative et leur sens (explicite et implicite). À l'exception peut-être de certaines interprétations psychologiques (influencées probablement par Edmond Ortigues, Jacques Lacan ou même Roger Bastide), les analyses développées dans ces différents chapitres n'ont pas vieilli et restent étonnamment pertinentes, un demi-siècle plus tard. Une telle démarche est par ailleurs à l'opposée de la quête, par Griaule et Dieterlen, d'un mythe dogon unique et invariable quels que soient le contexte d'énonciation et l'identité du locuteur. De ce point de vue, Ethnologie et langage est l'antithèse de Renard pâle.

7 Comparée aux travaux de l'École Griaule, cette monographie sur la parole donne ainsi une autre vision des Dogon. Au lieu de promouvoir l'image d'une tradition " pure » et d'une société figée, sans conflits ni individualités, ce livre souligne au contraire l'inventivité des chanteurs, la variabilité des récits, la diversité des personnalités et l'influence de l'islam sur la littérature orale (avec, par exemple, la transcription et la traduction d'un récit sur la création d'Adam et Ève). L'ouvrage décrit également des affaires de diffamation, de conflits intervillageois et de querelles entre époux ou coépouses en retraçant parfois la genèse de ces histoires ainsi que leurs règlements ("traditionnels", administratifs ou innovants). Enfin, à plusieurs reprises, l'auteure analyse les choix personnels de ses informateurs en prenant en compte le poids de l'enquête. En définitive, seul le politique est quasiment absent des analyses proposées par l'auteure, mais, en France, cette dimension des recherches ethnolinguistiques ou des études sur la littérature orale ne se développe vraiment qu’à la fin des années 1970.

En insistant davantage sur l'aspect novateur de cet ouvrage plutôt que sur sa filiation avec les travaux antérieurs de Griaule, ou encore en passant rapidement sur les critiques concernant son approche psychologique, cette recension aux allures de relecture ne se veut pas exhaustive. Elle cherche surtout à expliquer pourquoi, contrairement aux livres de Griaule, Ethnologie et langage reste une référence fondatrice pour de nombreux chercheurs français ou africains travaillant sur la littérature orale, $a$ fortiori si leurs recherches concernent le pays dogon. Elle vise aussi à souligner la diversité des influences, parfois contradictoires, qui traversent cette thèse. La composition de son jury en est d'ailleurs une illustration partielle ${ }^{1}$ en dépit de l'absence de Lévi-Strauss, avec la présence de Georges Balandier (fondateur de l'anthropologie dynamique), André Leroi-Gourhan (archéologue mais aussi anthropologue des 
techniques), Roger Bastide (sociologue des religions proche de l'ethnopsychiatrie) et enfin Maurice Houis et André Martinet, tous deux linguistes.

\section{NOTES}

1. Communication orale de Geneviève Calame-Griaule. 